\title{
Study on the Corrosion Resistance of 39SiCrVTiA High strength and high toughness spring steel
}

\author{
Lun $\mathrm{Nie}^{1,}{ }^{*}$, Min Zhu ${ }^{2}$, Shirun Tu ${ }^{1}$, Kefeng Yuan ${ }^{1}$, Kexin $\mathrm{Lu}^{1}$ \\ ${ }^{1}$ Zhejiang Meili High Technology Co., Ltd, Xinchang 312500, China \\ ${ }^{2}$ School of Mechanical Engineering \& Automation, Zhejiang Sci-Tech University, Hangzhou 310018, China
}

\begin{abstract}
SiCrVTiA spring steel is heat-treated and compared with the existing high-strength spring steels 60Si2CrVA and SAE9254 for electrochemical impedance spectroscopy (EIS), polarization curve and slow strain rate testing (SSRT). The test results of electrochemical impedance spectroscopy (EIS), polarization curve show that the corrosion resistance of 60Si2 CrVA was the best, followed by that of SAE9254 and 39SiCrVTIA.However, the test results of the SSRT test show that the three spring steels in $5 \% \mathrm{NaCl}$ solution possess high SCC susceptibility. The SCC susceptibility of 39SiCrVTiA steel is slightly lower and the stress corrosion ability is better than the other two steels which may be related to its containing Ti, V elements and lower carbon content.
\end{abstract}

Keywords: 39SiCrVTiA, heat-treated, electrochemical impedance spectroscopy (EIS)

\section{Introduction}

High strength spring steel is widely used in railway, automobile, engineering machinery and other machinery manufacturing[1].This kind of spring steel, has been implemented in the high-stress design, such as the spiral spring for automobile suspension, but the further improving the strength index of steel has been greatly restricted. With the increase of spring stress, the sensitivity of spring steel to corrosion has increased rapidly, and the problem of corrosion fatigue failure during the process has attracted attention. Therefore, higher strength and better corrosion fatigue resistance will become the main research direction of new spring materials.

According to the current high-performance, highreliability and lightweight development trends of various types of mechanical devices, this paper develops alloy spring steel with high strength, high toughness and good corrosion resistance. In the research and development of the current high-end spring products such as automotive and rail transit damping spring and stabilizer rod, the latest concept requirements of performance are put forward, enhancing the strength and toughness of the material at the same time pay attention to improve the spring material corrosion resistance to meet the needs of high reliability and lightweight mechanical products.

At present, 55SiCrA and 60Si2CrVAT are used as spring steels. The $55 \mathrm{SiCrA}$ steel has unstable strength and poor corrosion resistance, while the 60Si2CrVAT steel has the characteristics of high strength but insufficient plastic toughness, hydrogen embrittlement resistance and corrosion fatigue resistance. Therefore, the research and development of spring steel with high strength, high toughness and corrosion resistance has important practical engineering significance and good academic value. In view of the above situation, in order to improve the lowtemperature toughness of the material and ensure the durability of the coil spring in the corrosive environment, the 39SiCrVTiA spring steel with high strength and toughness has been developed.

\section{Test Method}

This paper mainly uses various testing methods to comprehensively evaluate the various properties of the 39SiCrVTiA spring steel developed, with special attention to corrosion resistance. And compared with the high-strength spring steel 60Si2CrVA and SAE9254 commonly used today, it provides relevant reference basis and data support for the promotion and application of this material. The experimental materials are 39SiCrVTiA, 60Si2CrVA and SAE9254 spring steels with $\phi 15.8 \mathrm{~mm}$. The material is quenched and tempered, and the structure is tempered troostite. The specific chemical components are shown in table 1. 39SiCrVTiA also contains Ni 0.22, $\mathrm{Cu} 0.23$ and Ti 0.049 .

Table 1. Chemical compositions of 39SiCrVTiA, 60Si2CrVA and SAE9254 spring steels (mass fraction, \%)

\begin{tabular}{ccccccccc}
\hline Steel & $\mathrm{C}$ & $\mathrm{Si}$ & $\mathrm{Mn}$ & $\mathrm{Cr}$ & $\mathrm{S}$ & $\mathrm{P}$ & $\mathrm{V}$ & $\mathrm{Fe}$ \\
\hline 39SiCrVTA & 0.39 & 1.75 & 0.64 & 0.73 & 0.003 & 0.006 & 0.06 & Bal. \\
60Si2CrVA & 0.56 & 1.56 & 0.62 & 1.02 & 0.009 & 0.012 & 0.16 & Bal. \\
SAE9254 & 0.55 & 1.50 & 0.65 & 0.80 & 0.009 & 0.01 & -- & Bal. \\
\hline
\end{tabular}

\footnotetext{
* Corresponding author: lun.nie@china-springs.com
} 
The electrochemical test instrument is a PARSTAT 2273 electrochemical workstation. The sample size is $\phi 15.8$ $\mathrm{mm} \times 5 \mathrm{~mm}$. Use a welding gun and a tin wire to solder the back of the test surface of the sample to the copper wire, and seal it with epoxy resin and ethylenediamine. The electrochemical test adopts a three-electrode system, saturated calomel electrode(SCE) as the reference electrode, graphite as the auxiliary electrode, and the sample to be tested is the working electrode. Before the experiment, the working electrode was first polished by $\mathrm{SiC}$ water abrasive paper from $150 \#$ to $1500 \#$, then cleaned by ethanol and deionized water, and then dried by cold air for later use. The experimental medium is a $5 \%$ (mass fraction) $\mathrm{NaCl}$ solution at $35{ }^{\circ} \mathrm{C}$. During the experiment, the temperature of the medium is controlled by a constant temperature water bath with digital display. Before the test, the sample is polarized at $-1000 \mathrm{mV}$ for 3 minutes. The electrochemical impedance spectroscopy (EIS) test frequency range is $105 \sim 10-2 \mathrm{~Hz}$, and the excitation signal amplitude is $10 \mathrm{mV}$. The EIS test is performed under open circuit potential. The impedance data is shown by Nyquist and Bode diagram. The circuit component codes were used to describe the data, and the equivalent circuit was fitted and analyzed with ZSLMPWLN software. When measuring the polarization curve, the potential scanning range is: $-1000 \sim-450 \mathrm{mV}$ (vs $\mathrm{SCE}$ ), and the scanning rate is $0.5 \mathrm{mV} \cdot \mathrm{s}-1$. The polarization curve results are analyzed by Tafel extrapolation.

The slow strain rate tensile test (SSRT) is carried out on the WDML-30KN material testing machine. The experiment uses a smooth plate-like tensile test specimen with a sample size prepared in accordance with GB/T 15970. Before the experiment, the surface of the sample is polished to 1500 \# by $\mathrm{SiC}$ water-resistant sandpaper, then cleaned with acetone, deionized water, and dried for later use. The experimental solution medium is $5 \% \mathrm{NaCl}$ (mass fraction). A three-electrode system was used, with the tensile sample as the working electrode, Pt sheet as the auxiliary electrode, and saturated calomel electrode (SCE) as the reference electrode. In SSRT experiment, the tensile samples are tested at the constant potential of $1000 \mathrm{mV}$ (vs SCE). The test samples were maintained at this potential until the samples fractured during the whole experiment, and the $\mathrm{CS} 350 \mathrm{H}$ electrochemical workstation is used to apply constant potential to the samples. The tensile strain rate is $1 \times 10-6 \mathrm{~s}-1$, and the test temperature is room temperature $\left(\sim 25^{\circ} \mathrm{C}\right)$. After the SSRT experiment, Quanta250 scanning electron microscope (SEM) is used to observe and analyze the fracture morphology of tensile samples.

After the experiment, the parameters of elongation loss I $\delta$ and section shrinkage loss I $\psi$ are used to evaluate the SCC sensitivity of spring steel, where I $\delta$ and $\mathrm{I} \psi$ are calculated according to the following formula.

$$
\begin{array}{r}
\mathrm{I}_{\delta}=\left(1-\frac{\delta_{\mathrm{E}}}{\delta_{0}}\right) \times 100 \% \\
I_{\psi}=\left(1-\frac{\psi_{\mathrm{E}}}{\psi_{0}}\right) \times 100 \%
\end{array}
$$

In the formula, $\delta \mathrm{E}$ and $\psi \mathrm{E}$ are the elongation and sectional shrinkage of spring steel in solution, and $\delta 0$ and $\psi 0$ are the elongation and sectional shrinkage of spring steel in air, respectively.

\section{Results and Analysis}

\subsection{Electrochemical test.}

Electrochemical impedance spectra test. Figure1 shows the electrochemical impedance spectra of three materials in a $5 \% \mathrm{NaCl}$ solution. The equivalent circuit Rs (QdlRt) in Figure2 is used to fit the impedance spectrum, where Rs is the solution resistance, Qdl is the electric double layer capacitance at the non-ideal electrode/solution interface, and Rt is the charge transfer resistance. In the actual electrochemical system, the frequency response characteristics of the double-layer capacitor at the electrode/solution interface are different from that of the pure capacitor, so the constant phase angle $\mathrm{Q}$ is often used to represent the double-layer capacitor. Figure3 shows the fitted charge transfer resistance Rt. It can be seen from Figure 3 that the value of the charge transfer resistance Rt of different materials is different. 39SiCrVTiA has the smallest Rt value, and the other two materials are closer. The smaller Rt is, the smaller the resistance during charge transfer is[2], and the lager the electrochemical reaction rate is, the lager the corrosion rate is[3]. Therefore, the order of the corrosion resistance of different materials is: 60Si2CrVA> SAE9254> 39SiCrVTiA.

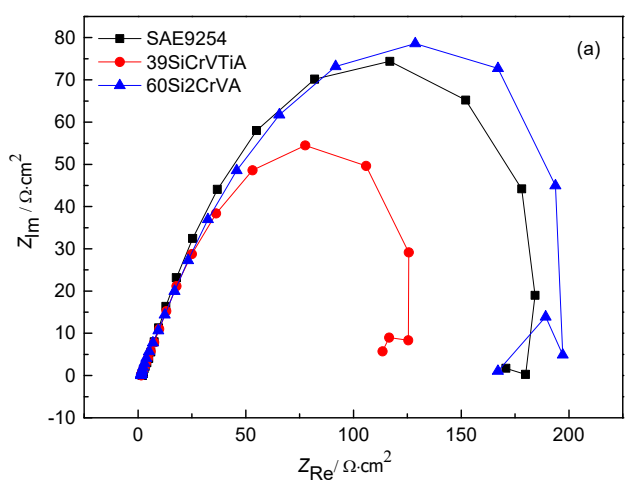

(a) Nyqulst plot

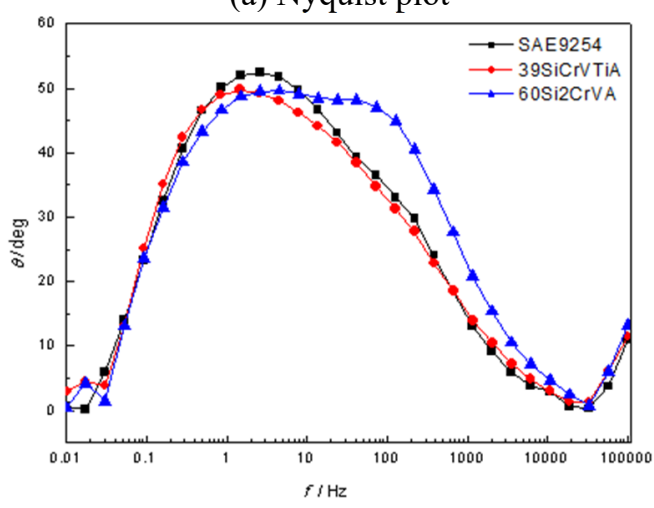

(b) Bode plot of phase angle 


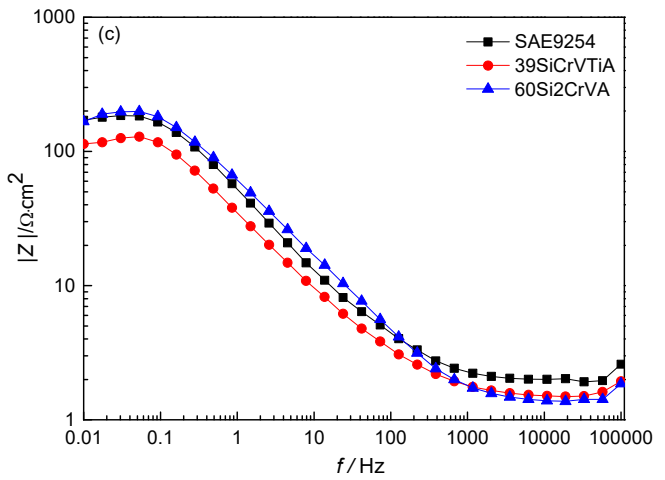

(c) Bode plot of $|\mathrm{Z}|$

Figure 1. Electrochemical impedance spectra of different materials in $5 \% \mathrm{NaCl}$ solution

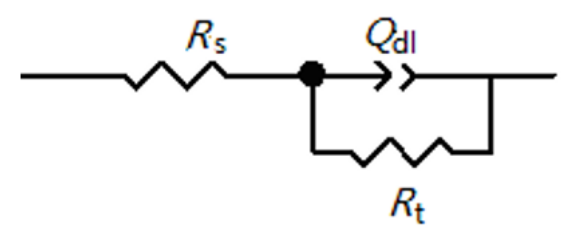

Figure 2. Electrochemical impedance spectroscopy simulation equivalent circuit

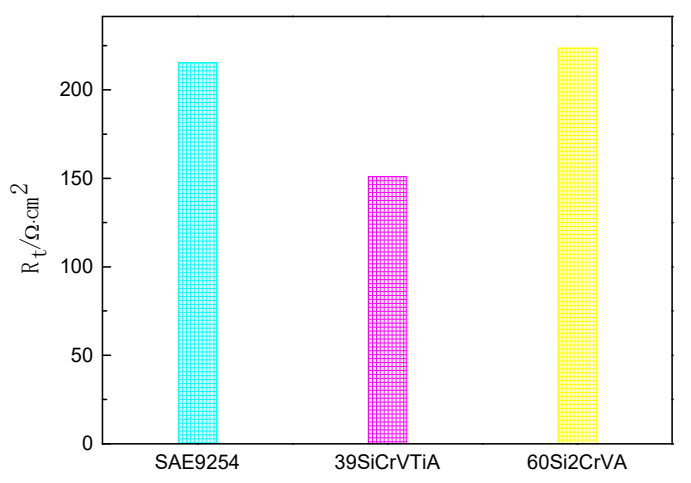

Figure 3. Fitted charge transfer resistance $\mathrm{R}_{t}$

Polarization curves test. Figure 4 shows the polarization curves of different spring steels in $5 \% \mathrm{NaCl}$ solution. Table 2 shows the corrosion potential Ecorr and corrosion current density Icorr of different spring steels in $5 \% \mathrm{NaCl}$ solution fitting from the polarization curves in Figure5. From the table 2 , it can be seen that the corrosion potential sequence from positive to negative is $60 \mathrm{Si} 2 \mathrm{CrVA}$, SAE9254 and 39SiCrVTiA, and the corrosion current density sequence from small to large is $60 \mathrm{Si} 2 \mathrm{CrVA}$, SAE9254 and 39SiCrVTiA.The more negative the corrosion potential is, the greater the thermodynamic tendency of corrosion is. The larger the corrosion current density is, the higher the corrosion rate is $[4,5]$. Therefore, the corrosion resistance order of different materials is 60Si2CrVA $>$ SAE9254 > 39SiCrVTiA.

Based on the above test results, spring steel $60 \mathrm{Si} 2 \mathrm{CrVA}$ has the best corrosion resistance, while the steel SAE9254 and 39SiCrVTiA has poor corrosion resistance. According to the chemical composition of the three spring steels, the composition of steel 39SiCrVTiA contains $\mathrm{Cu}$, $\mathrm{Ti}, \mathrm{Ni}$ and other elements. Relevant studies have shown that the addition of these three elements in material can improve the electrode potential [6-9], refine the grain and improve the compactness of the rust layer thus material corrosion resistance can be improved. Additionally, the reduction of carbon content in steel 39SiCrVTiA is also beneficial to improving its corrosion resistance. However, the actual test results show that the corrosion resistance of steel $39 \mathrm{SiCrVTiA}$ is worse than that of steel $60 \mathrm{Si} 2 \mathrm{CrVA}$. This may be related to the content of the other two elements. According to the chemical composition comparison, steel 60Si2CrVA has higher $\mathrm{Cr}$ and $\mathrm{V}$ content $(1.02 \%$ and $0.16 \%)$, while the $\mathrm{Cr}$ and $\mathrm{V}$ content of steel $39 \mathrm{SiCrVTiA}$ is only $0.73 \%$ and $0.06 \%$ respectively. As is known to all, element $\mathrm{Cr}$ is the key element to improving the corrosion resistance of materials $[10,11]$, and its content greatly affects the corrosion resistance performance. Meanwhile the element $\mathrm{V}$ is useful for refining grains and reducing segregation, thus improving corrosion resistance to a certain extent. Therefore, the higher content of element $\mathrm{Cr}$ and $\mathrm{V}$ may account for the better corrosion resistance of spring steel 60Si2CrVA.

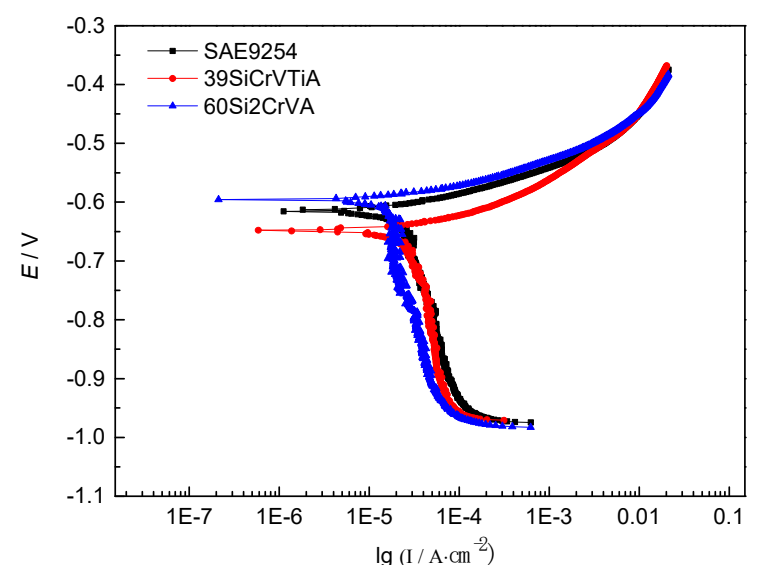

Figure 4. Polarization curves of different spring steels in 5\% $\mathrm{NaCl}$ solution

Table 2. Corrosion potential Ecorr and corrosion current density Icorr of three steels

\begin{tabular}{ccc}
\hline Steel & Ecorr $/ \mathrm{mV}(\mathrm{vs} \mathrm{SCE})$ & Icorr $/\left(\mu \mathrm{A} \cdot \mathrm{cm}^{-2}\right)$ \\
\hline 39SiCrVTiA & -651 & 29.8 \\
60Si2CrVA & -598 & 17.1 \\
SAE9254 & -614 & 23.1 \\
\hline
\end{tabular}

Stress corrosion test. Figure 5 shows the stress-strain curves of three spring steels in air and $5 \% \mathrm{NaCl}$ solution. According to the figure, the tensile strength and yield strength 0.2 of spring steel 39SiCrVTiA, 60Si2CrVA and SAE9254 is $1855 \mathrm{Mpa}$ and $1767 \mathrm{Mpa}, 2127 \mathrm{Mpa}$ and 1900 Mpa, $2073 \mathrm{Mpa}$ and $1845 \mathrm{Mpa}$ respectively. It can be observed that the stress-strain behavior of samples in air and solution (applying $-1 \mathrm{v}$ vs.SCE) is significantly different, and the elongation of samples in air is much higher than that in solution. When we carried on the slow strain rate tensile test (SSRT) of the three materials in 
$5 \% \mathrm{NaCl}$ solution, the samples fracture during the elastic deformation phase. This indicates that spring steels have a high stress corrosive cracking sensitivity under corrosion test condition.
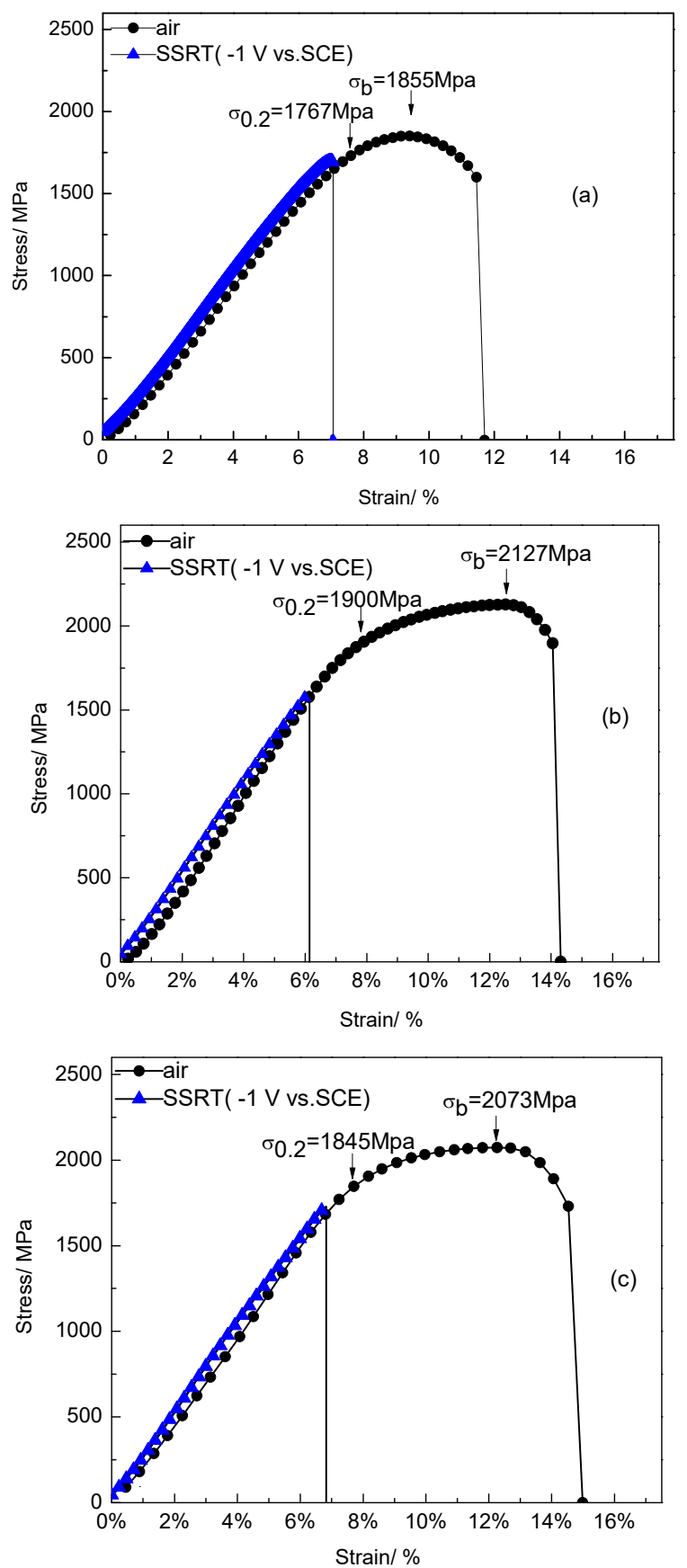

Figure 5. Stress-strain curves of three steels tested in air and $5 \% \mathrm{NaCl}$ solution (a) $39 \mathrm{SiCrVTiA}$; (b) $60 \mathrm{Si} 2 \mathrm{CrVA}$; (c) SAE9254.

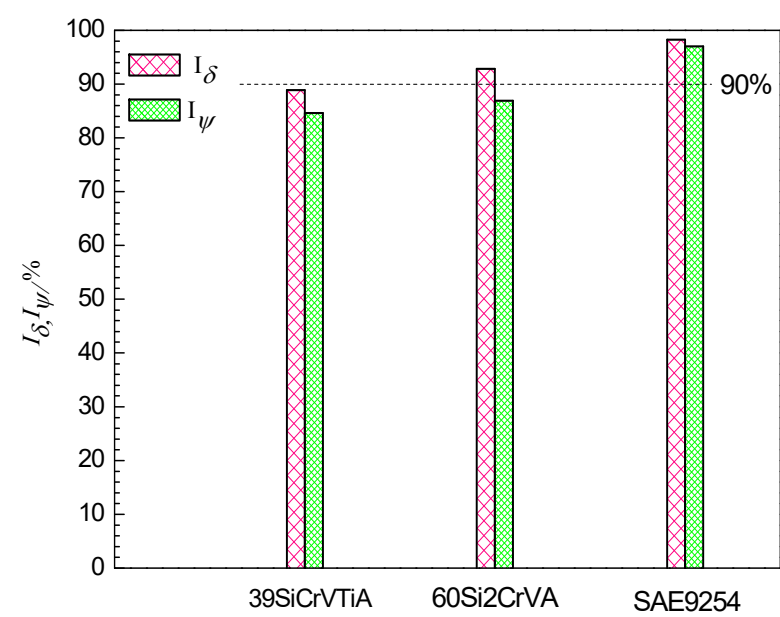

Figure 6. Elongation-loss rate $I \delta$ and area reduction loss rate $\mathrm{I} \psi$ of the three spring steels in $5 \% \mathrm{NaCl}$ solution

Figure 6 shows the elongation loss and section shrinkage loss of three spring steels in $5 \% \mathrm{NaCl}$ solution. From the figure, the spring steels $39 \mathrm{SiCrVTiA}$ and 60Si2CrVA in solution both have the very high elongation loss $I \delta$ and area reduction loss I $\psi$, while the steel SAE9254 has higher I $\delta$ and I $\psi$ that larger than $90 \%$, and SCC parameter values are the lowest. Combining with the Figure8, we can know that three spring steels all have higher SCC sensitivity under corrosion test condition, and steel 39SiCrVTiA has a slightly lower SCC sensitivity than the other spring steels. The high brittleness coefficient indicates that three spring steels brittle fracture.

Figure7 shows the fracture morphologies of spring steel $39 \mathrm{SiCrVTiA}$ in air and $5 \% \mathrm{NaCl}$ solution. It can be seen from Figure7(a)that the tensile fracture of steel 39SiCrVTiA in air has obvious necking and plastic deformation phenomenon. meanwhile. Figure7(b) shows a large number of dimples and micropores of different sizes which shows evident ductile fracture characteristics. Figure7(c) and (d) show that the fracture morphology of spring steel in $5 \% \mathrm{NaCl}$ solution is different from that in air. Compared with the fracture morphology in air, the fracture is more flat and there is no apparent necking phenomenon when it fractured in $5 \% \mathrm{NaCl}$ solution. Figure7(d) presents the typical intergranular crack morphology which looks like rock candy. The cracks extand along the grain boundary, and the grain separation phenomenon also can be observed, which are characteristics of Intergranular Stress Corrosion Crack(IGSCC) [12,13]. After observing of Figure7(e) in detail, it can be seen that the cracks in the local region are wide and deep, and the short cracks are connected with each other to grow into long cracks, and the extension path is similar to the linear form, which are the obvious hydrogen embrittlement cracking characteristics (HE)[14]. Therefore, the SCC process presents the characteristics of intergranular brittle cracking and hydrogen embrittlement cracking at the same time, and its SCC sensitivity is relatively high. 

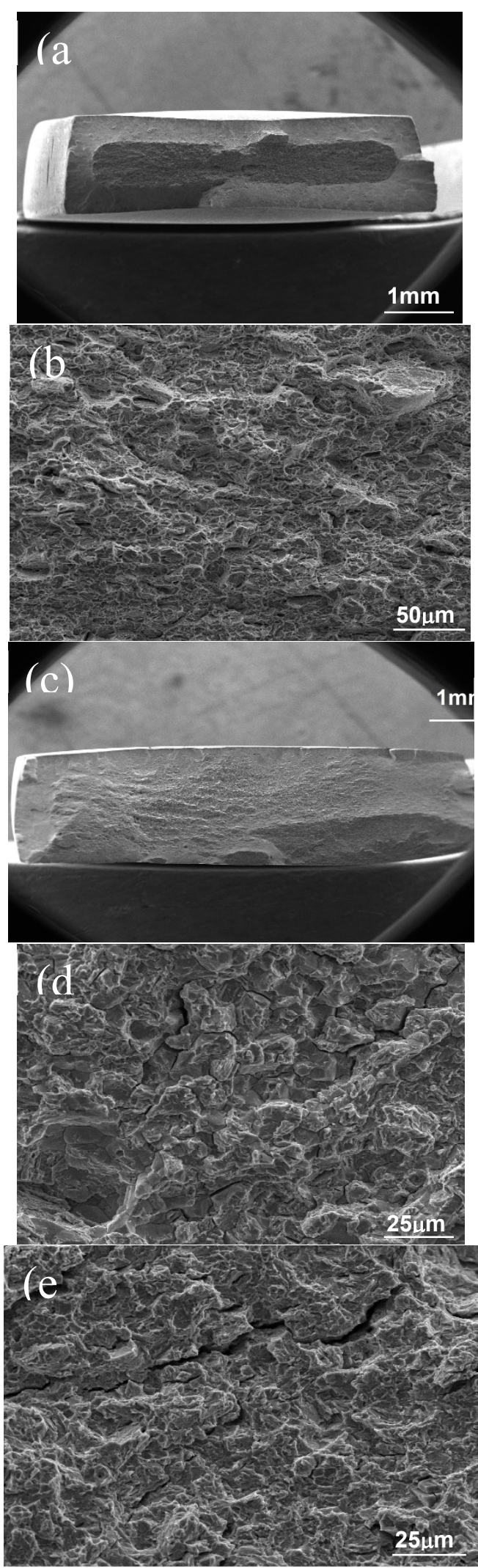

Figure 7. Fracture morphologies of steel $39 \mathrm{SiCrVTiA}$ tested in air $(\mathrm{a}, \mathrm{b})$ and $5 \% \mathrm{NaCl}$ solution(c-f)

Figure 8 shows the fracture morphology of spring steel 60 Si2 CrVA in air and $5 \% \mathrm{NaCl}$ solution. It can be seen from Figure 8(a) and(b) that the tensile fracture of steel $60 \mathrm{Si} 2 \mathrm{CrVA}$ in air also has obvious necking and plastic deformation phenomenon, and large number of dimples and micropores of different sizes and depth which shows ductile fracture characteristics. Figure8(c) and (d) show that the fracture morphology of steel 60Si2 CrVA in $5 \% \mathrm{NaCl}$ solution is significantly different from that in air. The fracture in air shows obvious ductile fracture characteristics like necking phenomenon; however, in $5 \% \mathrm{NaCl}$ solution, the fracture shows no necking phenomenon. Figure8(d) shows the typical ice-sugar-like intergranular cracking morphology, with many cracks extending along grain boundaries and obvious grain separation, which are obvious characteristics of Intergranular Stress Corrosion Crack (IGSCC). After observing the Figure8(e) and 8(f) in detail, it also can be seen that apart from obvious characteristics of IGSCC , there are also existing some characteristics of Transgranular Stress Corrosion Cracking (TGSCC) $[15,16,17]$ in the local region. Transgranular cracks are long, deep and wide when they almost extend in a continuous linear form, which show the obvious hydrogen embrittlement cracking characteristics (HE).Then, if combined with Figure7 and 8, it can be seen that when $-1 \mathrm{v}$ (vs.SCE) is applied in SSRT process, the spring steel 60Si2CrVA has a high SCC sensitivity in $5 \% \mathrm{NaCl}$ solution, and presents obvious characteristics of intergranular brittle cracking and hydrogen embrittlement cracking.

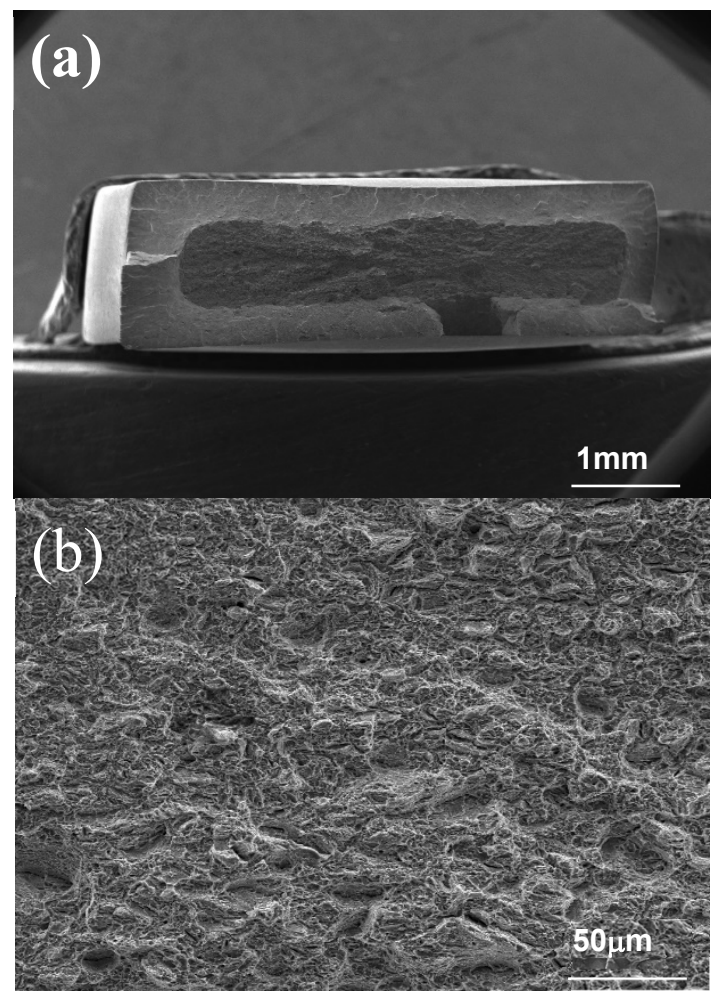



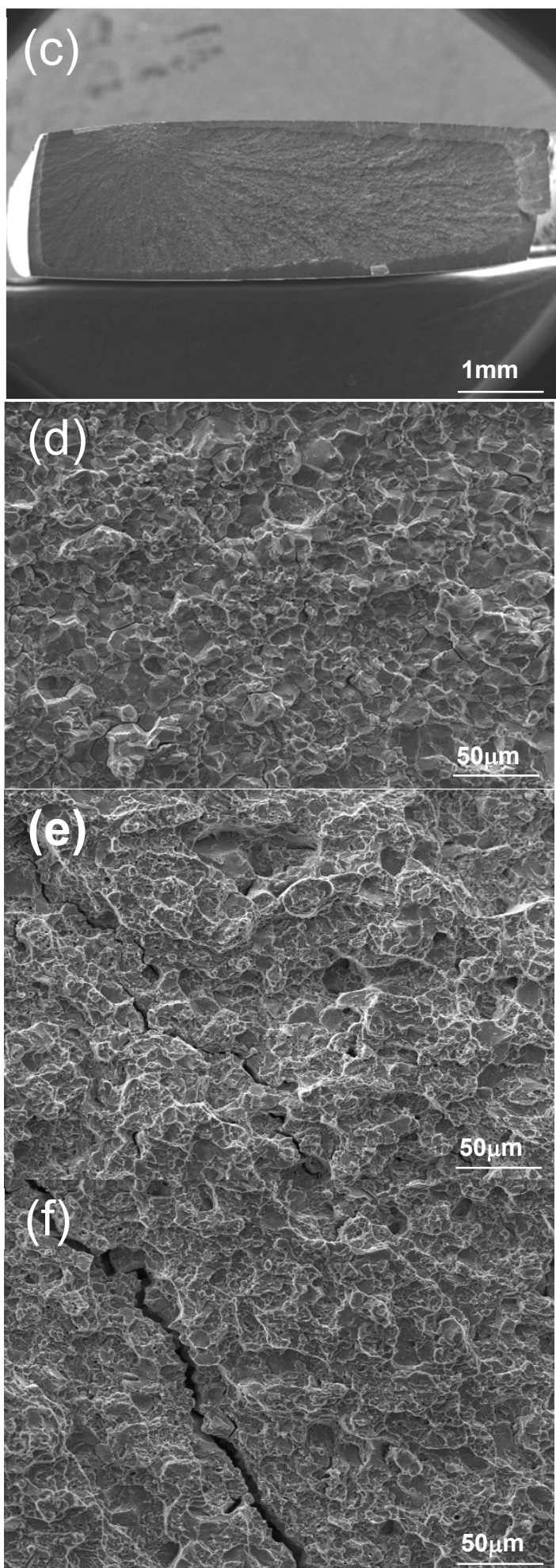

Figure 8. Fracture morphologies of steel $60 \mathrm{Si} 2 \mathrm{CrVA}$ tested in air $(\mathrm{a}, \mathrm{b})$ and $5 \% \mathrm{NaCl}$ solution(c-f)

Figure 9 shows the fracture morphology of spring steel SAE9254 in air and $5 \% \mathrm{NaCl}$ solution. It can be seen from Figure9 (a) and (b) that it is similar to the steel 60Si2CrVA, the steel SAE9254 fracture in the air also presents necking and plastic deformation phenomenon, as well as a large number of dimples and micropores, which on behalf of the ductile fracture. Figure9(c) and (d) show that the fracture of SAE9254 steel in $5 \% \mathrm{NaCl}$ solution is flat without necking phenomenon, and there is obvious grain separation, which are typical characteristics of hydrogen embrittlement. In addition, Figure9 (e) also shows that long, deep and wide transgranular cracks extending in a straight line. This indicates that the fracture characteristics of steel SAE9254 both have the characteristics of intergranular brittle cracking and transgranular cracking, in the form of mixture of shallow intergranular crack extention and deep transgranular crack extention. It is shown that steel SAE9254 has higher I $\delta$ and $\mathrm{I} \psi$ value, and presents the obvious characteristics of hydrogen embrittlement cracking combined with Figure8. So when we apply 1V (vs. SCE) in the process of the SSRT, the steel SAE9254 shows more SCC sensitivity in $5 \% \mathrm{NaCl}$ solution.

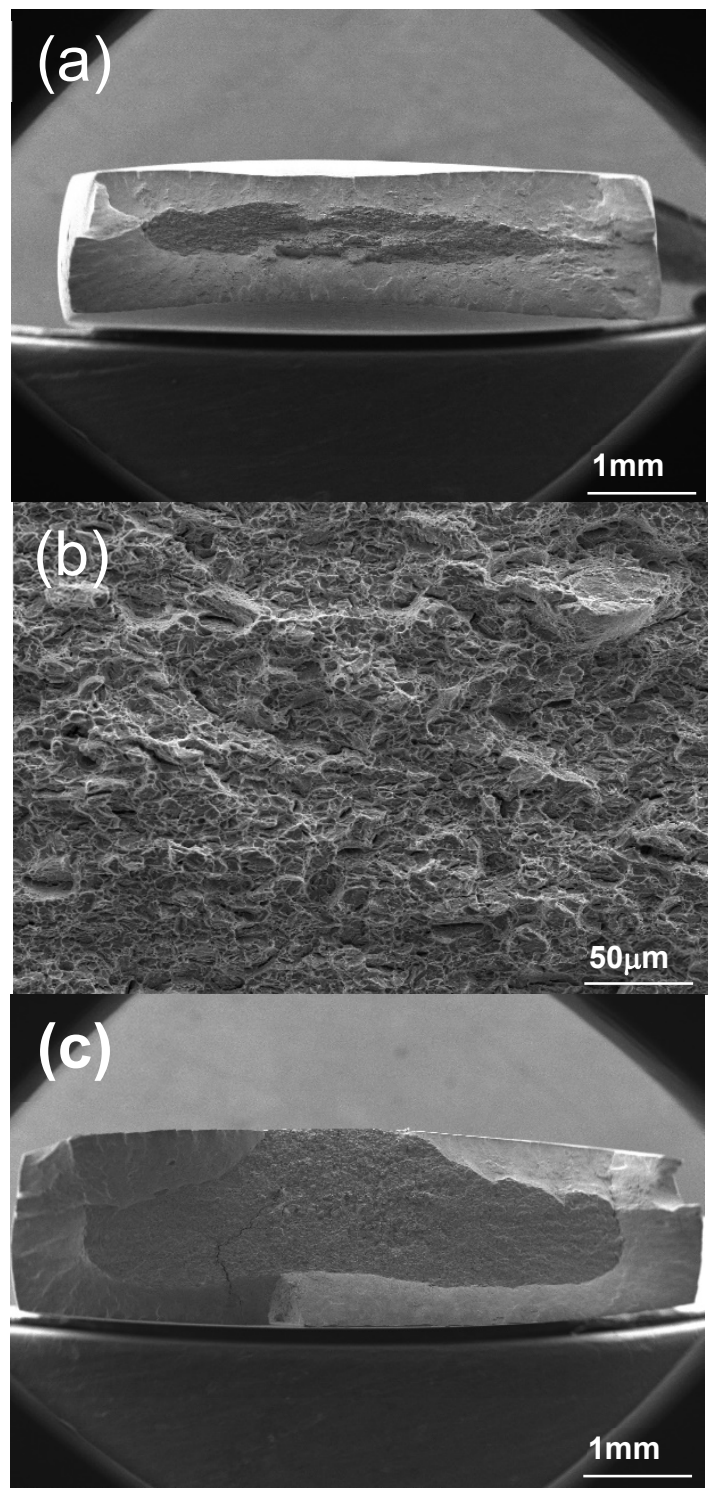




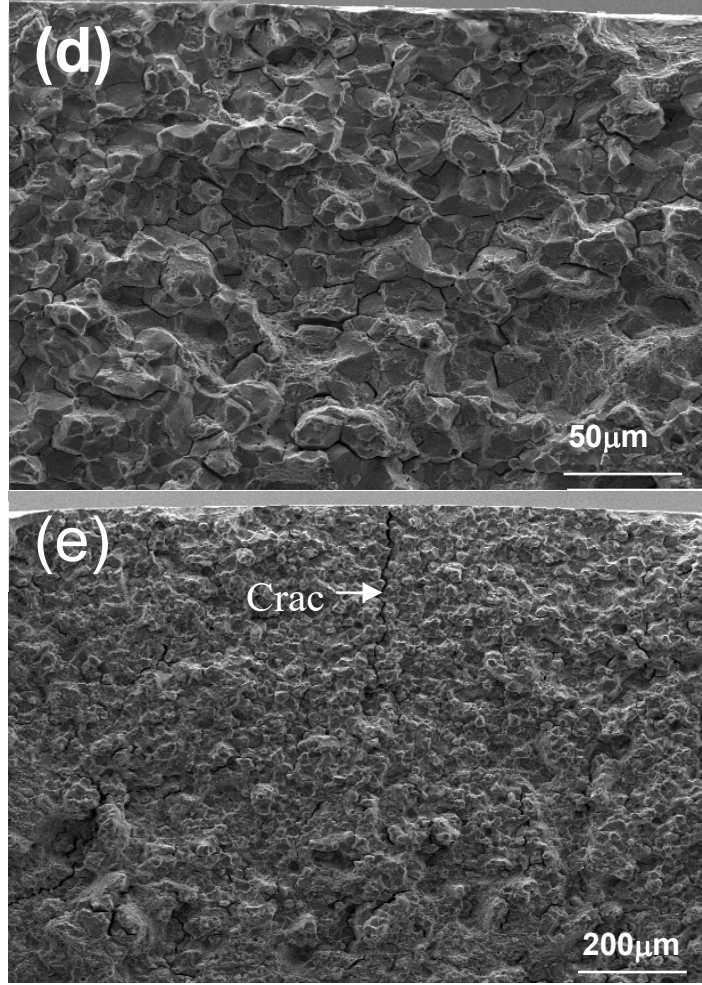

Figure 9. Fracture morphologies of steel SAE9254 tested in air $(\mathrm{a}, \mathrm{b})$ and $5 \% \mathrm{NaCl}$ solution (c-e)

\subsection{Discuss}

According to the polarization curve (Figure 4), when the potential reaches $-1 \mathrm{~V}$ (vs, the steels will react as the cathode as shown below.

$$
\begin{aligned}
2 \mathrm{H}_{2} \mathrm{O}+2 \mathrm{e}- & \rightarrow 2 \mathrm{H}+2 \mathrm{OH}- \\
\mathrm{H}+\mathrm{H} & \rightarrow \mathrm{H} 2
\end{aligned}
$$

The partly $\mathrm{H}$ generated in the process of cathode hydrogen evolution will be adsorbed, then it penetrates into the steel and spreads along the grain boundary. In the SSRT process, on the influence of stress, the diffusion of $\mathrm{H}$ atom is intensified, and it tends to gather at the grain defect (grain boundary), which will lead to stress concentration and generate a large number of tiny grain boundary cracks in the steel (Figure7(d), 8(d) and 9(d)). In addition, due to the stress-induced diffusion, $\mathrm{H}$ atom is more likely to diffuse and accumulate at the crack tip, and it will promote the rapid propagation of the crack tip, then the tendency of hydrogen embrittlement increases and it will lead to the occurrence of transgranular brittle fracture (Figure7 (e), $8(\mathrm{e}), 8(\mathrm{f})$ and $9(\mathrm{e}))$. If we combine the brittle fracture characteristics in Figure7, 8 and 9 with the relatively large values of section shrinkage loss and elongation loss in Figure6, it can be inferred that when spring steel is applied to $-1 \mathrm{~V}$ (vs.SCE) in the $5 \% \mathrm{NaCl}$ solution, the SCC mechanism is mainly reflected as hydrogen embrittlement mechanism (HE).

Additionally, it can be seen from table 1 that the main difference in chemical composition of spring steel 60Si2CrVA and SAE9254 is that steel 60Si2CrVA contains V element, while steel SAE9254 does not. In addition to refining grains, reducing segregation and improving strength and toughness, the element $\mathrm{V}$ is also the element forming the strong carbide, stable tiny precipitates which avail to the formation of hydrogen capture traps and then affect the diffusion and distribution of hydrogen in steel leading to the effectively reducing the sensitivity of delayed fracture of steel[18,19]. This may be the reason for the higher SCC sensitivity of steel SAE9254 under the experimental conditions in this paper. While spring steel 39SiCrVTiA contains element Ti, which has a similar function to $\mathrm{V}$. The addition of Ti can increase the number of hydrogen traps and improve toughness, thus improving its resistance to hydrogen brittleness. Additionally, the steel 39SiCrVTiA has the lowest carbon content, which is also conducive to improving the hydrogen brittleness resistance. Therefore, the SCC sensitivity of 39SiCrVTiA steel is lower than that of the other two materials.

\section{Conclusion}

The results of the long period immersion test show that the corrosion rates of the three spring steels are similar, and the steel SAE9254 has the highest corrosion rate, followed by $39 \mathrm{SiCrVTiA}$ and $60 \mathrm{Si} 2 \mathrm{CrVA}$ steels. Electrochemical ac impedance spectrum and polarization curve tests all show that the corrosion resistance sequence of spring steel materials from strong to weak was 60Si2CrVA > SAE9254 > 39SiCrVTiA.

When $-1 \mathrm{~V}$ (vs.SCE) was applied in SSRT process, all three spring steels had high SCC sensitivity in $5 \% \mathrm{NaCl}$ solution. The SCC sensitivity of steel $39 \mathrm{SiCrVTiA}$ was slightly lower, while the SCC sensitivity of steel SAE9254 was largest. The SCC mechanism is mainly hydrogen embrittlement (HE). The lower SCC sensitivity of $39 \mathrm{SiCrVTiA}$ steel may be related to its elements Ti, V and low carbon content.

To sum up, 39SiCrVTiA spring steel is a kind of high strength and high toughness spring steel, which has excellent plastic toughness especially under low temperature condition and it also has the better hydrogen embrittlement resistance. However, its corrosion resistance remains to be improved.

\section{References}

1. Ouyang Zhengrong, Zhai Zhenglong, Zhu Jingjun. A brief analysis of the development status and technical points of spring steel[J]. Laigang Science \& Technology, 2013,(6):7-10.

2. Ouyang W Z. Equivalent circuit for EIS study on rusted marine cast iron artifacts [J]. Advance Materials Research, 2015, 1094: 316-319.

3. West W C, Hood Z D, Adhikari S P, et al. Reduction of charge-transfer resistance at the solid electrolyte electrode interface by pulsed laser deposition of films from a crystalline Li2PO2N source [J]. Journal of Power Sources, 2016, 312: 116-122.

4. Liu Shuan,Zhao Xia,Chen Changwei. Corrosion Behavior of Pipeline Steel X65 in Oilfield[J]. Journal of Chinese Society for Corrosion and Protection, 2015,35(5):393-399. 
5. Yin Z F, Zhao W Z, Lai W Y, et al. Electrochemical behaviour of Ni-base alloys exposed under oil/gas field environments [J]. Corrosion Science, 2009, 51(8): 1702-1706.

6. Xu Dexian, Yin Zhongda. High Strengthening Spring Steel and Effect of Alloying Elements [J]. Heat Treatment of Meatails, 2003,28 (12): 30-36.

7. Yu Fuzhou. Corrosion resistance of Metal Materials [M]. Bei Jing:Science Press, 1982.

8. Xing Xianqiang. Present situation of low-alloy spring steel wire rod for domestic automobile [J]. Metal Products, 2010,(6):34-37.

9. Luo Xiong,Lin zhenyuan. The development of high strength corrosion resistant alloy material in the lightweight design of car suspension spring[C]. Wu $\mathrm{Xi}$ : Proceedings of the 23rd annual meeting of national metal products information network, 2013.

10. Huang Jianzhong, Zuo Yu. Corrosion resistance and corrosion data of materials [M]. Bei Jing: Chemical industry press, 2003, 81-84.

11. $\mathrm{Hu}$ Lihua, $\mathrm{Lu} \mathrm{MinXu,} \mathrm{Chang} \mathrm{Wei.} \mathrm{Effect} \mathrm{of} \mathrm{Cr}$ Content and Microstructures on the $\mathrm{CO} 2$ Corrosion Resistance of the Weld Joint of $1 \% \mathrm{Cr}$ Containing Pipeline Steel [J].Journal of Materials Engineering, 2010, (7): 82-86.

12. Wang J Q, Atrens A. SCC initiation for X65 pipeline steel in the "high" $\mathrm{pH}$ carbonate/ bicarbonate solution [J]. Corrosion Science, 2003, 45(10): 2199-2217.

13. Li J, Elboujdaini M, Fang B. Microscopy study intergranular stress corrosion cracking of X-52 line pipe steel [J]. Corrosion, 2006, 62(4): 316-322.

14. Chen W, King F, Vokes E. Characteristics of nearneutral-pH stress corrosion cracks in an X-65 pipeline [J]. Corrosion, 2002, 58(3): 267-275.

15. Guo Hao, Li Guangfu, Cai Xun. Stress Corrosion Cracking Behavior of X70 Pipeline Steel in NearNeutral Ph Solutions at Different Temperatures [J]. ACTA METALLURGICA Sinice, 2004, 40(9): 967971.

16. Dmytrakh I M. Corrosion fracture of structural metallic materials: effect of electrochemical conditions in crack [J]. Strain, 2011, 47(s2): 427-435

17. Tang X, Cheng Y F.Quantitative characterization by micro-electrochemical measurements of the synergism of hydrogen, stress and dissolution on near-neutral $\mathrm{pH}$ stress corrosion cracking of pipelines [J]. Corrosion Science, 2011, 53(9): 2927-2933.

18. Hui W J, Dong H, Weng Y Q, et al. Delayed fracture behavior of CrMo type high strength steel containing titanium [J]. Journal of Iron and Steel Research Inter, 2005, 12(1):43-49.

19. Xian Aiping, Li Peiji, Li Xun. Trapping of Hydrogen by Precipitate TiC in Low Carbon Steel[J].ACTA METALLURGICA Sinice, 1986, 22(3): A181-187. 